\title{
ARTIGO
}

\section{Uma conversa com Menelick de Carvalho Netto e Juarez Guimarães no marco dos 30 anos da Constituição de 1988}

Almir Megali Neto ${ }^{1}$ | Jessica Holl ${ }^{2}$ Rayann Kettuly Massahud de Carvalho ${ }^{3}$

Como citar este artigo: NETO, Almir Megali; HOLL, Jessica; CARVALHO, Rayann Kettuly Massahud de. Uma conversa com Menelick de Carvalho Netto e Juarez Guimarâes no marco dos 30 anos da Constituição de 1988. Revista de Ciências do Estado. Belo Horizonte: v. 5, n. 2, e20030. ISSN: 2525-8036.

Resumo: O presente trabalho tem como objetivo justapor as principais ideias expostas pelos Professores Menelick de Carvalho Netto e Juarez Guimarães acerca dos 30 anos da Constituição de 1988, presentes em seus artigos contidos na obra "O Que Constituímos? Homenagem a Menelick de Carvalho Netto nos 30 Anos da Constituição de 1988" (CATTONI DE OLIVEIRA; GOMES, 2019) e nas entrevistas por eles concedidas à Revista de Ciências do Estado da Universidade Federal de Minas Gerais (nos anos de 2018 e 2019). A partir do estudo destas obras, conclui-se que, apesar de suas concepções acerca da Constituição brasileira inicialmente indicarem uma divergência, na verdade, ambos demonstram a mesma lealdade constitucional, partindo, contudo, de conceitos distintos sobre a própria ideia de constitucionalismo. A partir desse diálogo é possível também concluir pela necessidade de compreender o atual momento do constitucionalismo brasileiro a partir das conquistas obtidas com o projeto de Constituição inaugurado em 1988. Assim, é imperativa a utilização da própria Constituição, posta em um momento de especial tensionamento, como ferramenta para a defesa da democracia e da ordem constitucional.

Palavras-chave: 30 anos da Constituição; Menelick de Carvalho Netto; Juarez Guimarães.

\footnotetext{
${ }^{1}$ Graduado e Mestre em Direito pela Universidade Federal de Minas Gerais.

2 Professora Substituta de Direito na UFOP. Professora Orientadora do Núcleo de Assessoria Jurídica de Ouro Preto (NAJOP/UFOP). Coordenadora do Grupo de Estudos em Transições e Autoritarismos. Pesquisadora do Centro de Estudos em Justiça de Transição da UFMG (CJT/UFMG). Mestre em Direito pelo Programa de PósGraduação em Direito da UFMG. Graduada em Direito pela UFMG. Membro da Associação Visibilidade Feminina. Advogada.

${ }^{3}$ Mestre em Direito pela UFMG. Bacharel em Direito pela UFLA. Membro do Núcleo de Estudos Direito, Modernidade e Capitalismo (UFMG) e do Grupo de Pesquisa Trabalho e Capital (UFMG).
} 


\section{INTRODUÇÃO}

Em 05 de outubro de 1988 foi promulgada a Constituição da República Federativa do Brasil. A data marca a ruptura com o regime autoritário instaurado pelo golpe civil-empresarialmilitar de 1964 e o início de um processo inclusivo e participativo que abriu caminho para a construção de um Estado Democrático de Direito. No contexto dos 30 anos da Constituição, dos debates sobre as conquistas obtidas nesse período e dos desafios que ainda precisam ser enfrentados, o presente artigo pretende propor um diálogo entre Menelick de Carvalho Netto e Juarez Guimarães. Esse diálogo tem como base os artigos publicados pelos dois professores na obra "O Que Constituímos? Homenagem a Menelick de Carvalho Netto nos 30 Anos da Constituição de 1988" (CATTONI DE OLIVEIRA; GOMES, 2019), assim como nas entrevistas concedidas pelos Professores à Revista de Ciências do Estado da Universidade Federal de Minas Gerais (2018 e 2019).

Dessa forma, pretende-se discutir as propostas dos dois professores, a partir de sua própria compreensão do que significa a Constituição e das possibilidades para o projeto constituinte de 1988. Para tanto, inicialmente, serão apresentados os principais elementos trabalhados por Menelick de Carvalho Netto nas duas obras mencionadas; na sequência serão apresentadas as contribuições que Juarez Guimarães também trás nas obras em estudo; e, por fim, será proposto um diálogo entre as contribuições dos dois autores para os 30 anos da Constituição de 1988. Por se tratar de pesquisa eminentemente bibliográfica, a metodologia utilizada é a revisão de literatura, tendo como base os artigos e entrevistas mencionados acima. A escolha dos artigos objeto do presente estudo foi motivada pelo fato deles serem trabalhos elaborados especificamente no contexto dos 30 anos da Constituição de 1988, com o objetivo de problematizar os 30 anos da Constituição.

\section{MENELICK DE CARVALHO NETTO NOS 30 ANOS DA CONSTITUIÇÃO}

A celebração das primeiras três décadas de vigência da Constituição de 1988 propicia uma reflexão sobre a tensão que se estabelece, no interior do próprio movimento do 
constitucionalismo, entre a pretensão de permanência das constituições e as aspirações por mudança do tempo presente. Essa tensão é inafastável, pois a constituição não se limita ao texto, a constituição "é mais que um texto" (CARVALHO NETTO, 2019, p. 384), ela expressa a própria sociedade — "que só se reproduz produzindo mudança, incorporando riscos" (CARVALHO NETTO, 2011, p. 42). Assim, a pretensão de permanência precisa ser reinterpretada, na medida em que "permanente é apenas o que é mutável, o que é capaz de receber novos sentidos nos novos contextos incessantemente produzidos" (CARVALHO NETTO, 2011, p. 42).

Mesmo diante da possibilidade de constantes de mudanças, a constituição permanece vinculada aos compromissos assumidos pelas gerações passadas e às suas próprias expectativas em relação ao futuro - de uma sociedade mais livre e menos desigual. O Direito Constitucional, portanto, é o local de encontro das aspirações daqueles e daquelas que já foram, daqueles e daquelas que aqui estão e daqueles e daquelas que ainda virão. Isso quer dizer que "um texto constitucional não aprisiona o futuro: pelo contrário, releituras são possíveis e a tendência é essa" (CARVALHO NETTO, 2018, p. 351), pois o "Direito Constitucional é vida; ou é vida, ou não é nada." (CARVALHO NETTO, 2003, p. 141).

É justamente essa a aposta de Menelick de Carvalho Netto (2019, p. 383-387), no marco dos trinta anos de vigência da Constituição de 1988: lançar luzes para o papel desempenhado pela Constituição dentro de um enquadramento mais abrangente. Para Carvalho Netto, trata-se, na verdade, de um campo aberto a múltiplas interpretações. De um campo constantemente em disputa, principalmente quando se tem em vista a dificuldade de estabelecer fundamentos incontroversos para os sistemas constitucionais contemporâneos. Isso faz da transição política e do processo de constitucionalização seguinte ao regime militar, um campo aberto a disputas de narrativas sobre o sentido normativo que se autoexpressa no processo de autodeterminação política que resultou na nova ordem constitucional instituída pela Constituição de 1988. E, em sendo assim, é preciso, desde já, advertir: "os 30 anos da Constituição não são simplesmente marcados por sucessos e implementações" (CARVALHO NETTO, 2019, p. 383).

Aliás, uma recuperação do próprio processo de elaboração deste texto constitucional revela que o seu traço característico é justamente marcado por esse embate de narrativas. Se por um lado há aqueles que, comprometidos com a narrativa oficial, defendem que a transição para a democracia somente teria sido possível em razão de um acordo pactuado entre as elites políticas do período, numa espécie de concessão deste grupo ao povo, por outro, há aqueles que 
apostam na reconstrução de elementos importantes da história constitucional brasileira para sustentar exatamente o contrário, ou seja, que a superação da ordem autocrática anterior somente foi possível pela mobilização de setores da sociedade civil organizada pelo fim do regime de exceção. Dessa maneira, pode-se dizer que, em verdade, a Constituição de 1988 é produto de um processo "profundamente participativo: formou-se efetivamente uma comunidade de interlocutores acerca de quem somos nós" (CARVALHO NETTO, 2019, p. 384).

Assim, enquanto para aquela chave de leitura a suposta ausência de manifestação de um poder constituinte originário faria do processo constituinte de 1987-1988 uma proposta meramente restauradora e da Constituição de 1988 uma continuação da ordem autoritária anterior, para esta chave de leitura, há elementos que possibilitam a compreensão desse fenômeno não apenas nos termos de uma continuidade. Há também elementos que apontam para um processo que não se limitou ao círculo interno das elites que compunham o regime anterior.

A disputa de narrativas em torno do sentido do processo de constitucionalização brasileiro não se encerrou com a promulgação do novo texto constitucional. Incompleto em si mesmo, como todo e qualquer texto, o texto constitucional, e aquilo que foi e pode ser constituído com base nele, continua a ser objeto de múltiplas interpretações. Interpretações essas que expressam as mais diversas visões de mundo dos sujeitos que compõem a sociedade brasileira. Muito antes de ser um empecilho à concretização do projeto constitucional inaugurado pela Constituição de 1988, esse grau de pluralismo na sociedade é condição de possibilidade para a sua própria existência.

Aqui se encontra o cerne da questão. Ora, apesar de deliberadamente pretender se opor às identidades pré-constituintes para forjar sua própria imagem, para se tornar viável em seu ambiente político-social, todo e qualquer projeto constitucional, inclusive o brasileiro, incorpora elementos dessa mesma tradição. Mesmo que os autores de uma nova ordem constitucional consigam deixar de fora de sua obra elementos da tradição pré-constituinte, se é que isso é possível, traços dessas outras identidades inevitavelmente surgiriam como resultado da interpretação e da elaboração de normas constitucionais no momento pós-constituinte. Então, por mais que o Direito Constitucional pretenda "controlar futuro e passado", para que haja "uma ruptura com o passado para que ele não volte e eu possa inaugurar o novo", sempre "é possível que o passado reentre, o risco é sempre esse" (CARVALHO NETTO, 2018, p. $354)$. 
A Constituição de 1988, elaborada pelo processo constituinte mais democrático de nossa história, tem enfrentado resistência, mesmo antes de sua entrada em vigor. $\mathrm{O}$ tom emancipatório expresso pelo seu texto não raramente é criticado como responsável por criar um país ingovernável. Seus "excessos" são tidos como responsáveis por criar um país que estaria permanentemente em um quadro de instabilidade político-institucional. ${ }^{4}$ Os ataques às bases garantistas desta Constituição são observados ainda hoje, passados mais de trinta anos da data de sua promulgação. A mesma tensão entre as forças conservadoras e progressistas observadas no momento de gestação do texto constitucional, apesar de renovada pelo inevitável processo de aprendizado social da sociedade brasileira com o Direito e a política no decorrer desses trinta anos, ainda se mostra presente e, certamente, não desaparecerá. Afinal, “não há garantia de nãoretrocesso, como algumas pessoas afirmam. O direito não é só uma luta, mas é luta permanente, direito não tem um curso único, tem vigilância permanente" (CARVALHO NETTO, 2019, p. 386).

Diante desse cenário, a proposta de Menelick de Carvalho Netto, no marco dos trinta anos da Constituição de 1988, é recuperar a tensão existente entre memória e esquecimento, para celebrar aquilo que pôde ser constituído com base neste texto constitucional. É claro que, talvez, poderia ter sido feito mais. Mas, também, parece inegável que, por outro lado, muito se fez em tal período em termos de conquistas democráticas. Para ilustrar esse processo de avanços e retrocessos observado no interior do próprio projeto constituinte inaugurado pela Constituição de 1988, o processo de elaboração do texto promulgado em 05 de outubro de 1988 é indicativo das disputas interpretativas que se desenvolveram em torno dele. Então, se hoje parece não ser possível frear os impulsos retrógrados das forças conservadoras, assim como não o foi possível durante o processo constituinte de 1987-1988, a solução para o tempo presente passa pela mesma aposta de trinta anos atrás: a exploração dos potenciais emancipatórios já presentes na facticidade dos processos políticos-sociais por parte de uma sociedade civil ativa.

Mas enfim, o que pode frear isso? Até para que entendamos ou resgatemos algum
peso que a Constituição de 1988 ainda tenha. Temos que comemorar o fato dela ter
aberto esse processo de aquisição e afirmação de direitos por todas as vias. É o plural
que não só aceita o pluralismo, mas sim busca o pluralismo: há algumas décadas no
Brasil, ninguém imaginava que isso pudesse ocorrer. E mesmo diante de um
diagnóstico extremamente sombrio que paira sobre nossa Constituição, sem dúvida,

\footnotetext{
${ }^{4}$ Representativo nesse sentido é o discurso do então Presidente da República, José Sarney, proferido em rede nacional de rádio e televisão, no dia 26 de julho de 1988, sobre o texto elaborado e aprovado em primeiro turno de votação pela Assembleia Constituinte. Disponível em: <https://www2.senado.leg.br/bdsf/bitstream/handle/id/120329/1988_26\%20a\%2031\%20de\%20Julho_032d.pdf? sequence $=3>$. Acesso em: 30 jan. 2020.
} 
nos últimos dois anos, continuo apostando na sociedade civil, ainda acredito que a saída continua a ser essa. Não há outra saída que não seja essa. E, nesse sentido, é necessário que tenhamos clareza quanto a tudo que já conquistamos e quanto à possibilidade de que uma sociedade civil cada vez mais atuante coloque freio no autoritarismo. Trata-se da defesa de algo extremamente difícil, uma vez que as conquistas ainda são percebidas como pequenas. Mas, quando colocamos em perspectiva uma história marcada fortemente pela exclusão - somos um dos países mais excludentes do mundo -, essas conquistas podem ser vistas como grandes vitórias. Um texto possibilita uma abertura, mas que só pode ter seu desenvolvimento e sentido através da luta.

Uma sociedade plural, complexa, está na base disso. Eu queria que fizéssemos esse esforço de ver a Constituição de 88 como isto: essa comunidade de princípios, complexa, densa, em permanente tensão - e não simplesmente um texto. O próprio processo de formação da Constituição, como já foi dito, é marcado por essa disputa, o que desde o início deixa essa marca de luta constante para a efetivação de direitos fundamentais (CARVALHO NETTO, 2019, p. 386-387) (Destaques do original).

Tendo como base as contribuições apresentadas por Carvalho Netto, parte-se, então, para um estudo da produção de Juarez Guimarães no marco dos 30 anos da Constituição. E, a partir da justaposição dos trabalhos de ambos os professores será, na sequência, proposto um diálogo entre eles.

\section{JUAREZ GUIMARÃES NOS 30 ANOS DA CONSTITUIÇÃO}

Para Juarez Guimarães, por sua vez, a reflexão em torno da efeméride dos trinta anos da Constituição de 1988 deve abarcar não apenas os avanços, mas, também, os retrocessos, a "sua efetividade" e o seu momento inaugural - como um momento dentro de uma tessitura temporal de um processo político de longo prazo ligado à "republicanização democrática do Brasil” (GUIMARÃES, 2019a, p. 249). Ou melhor, não deve circular apenas em torno do que fomos capazes de constituir nas últimas três décadas. Deve também ser acompanhada por indagações quanto ao que também não constituímos e sobre o que não fomos capazes de “impedir que se desconstituísse” (GUIMARÃES, 2019a, p. 249).

Para realizar esse complexo de reflexões é necessário entender dois elementos basilares. O primeiro está relacionado ao modo pelo qual uma constituição pode ser compreendida, isto é, com sendo "o lugar da institucionalização, por excelência, do conflito de vontades entre 'os que querem dominar e os que não querem ser dominados" (MAQUIAVEL, apud GUIMARÃES, 2019a, p. 249). O segundo, por sua vez, está relacionado à história brasileira, marcada pela violência expressa pelas desigualdades "racialista", "de gênero", "sociais" e "homofóbicas" - assumindo a tese de Marilena Chauí (GUIMARÃES, 2019a, p. 250). 
Assim, levando a sério que a Constituição é o espaço de conflito permanente e constante entre dominados e dominadas contra dominadores e dominadoras, os últimos trinta anos expressam, em grande medida, a vitória contra o legado de violência "que nos constitui desde a origem”. Em verdade, foi o período da história brasileira em que mais constituímos direitos (GUIMARÃES, 2019a, p. 250).

Contudo, apesar desses últimos anos terem sido um período de vitórias, segundo Juarez Guimarães, a Constituição de 1988 não revela apenas as nossas conquistas, mas carrega consigo tensões e contradições desde o seu momento inaugural até o momento presente (GUIMARÃES, 2019b, p. 08). Ela é "afirmadora de direitos" (GUIMARÃES, 2019b, p. 08), fundada em uma “cultura dos direitos humanos" (GUIMARÃES, 2019a, p. 250), expressando a institucionalização e a nacionalização dessa cultura — constituída em âmbito internacional "no pós-guerra" - , bem como a partir das experiências sociais brasileiras contra a ditadura civilempresarial-militar (GUIMARÃES, 2019b, p. 08). Ao mesmo tempo, todavia, essa mesma Constituição seria o resultado de uma "transição conservadora" (GUIMARÃES, 2019b, p. 08).

Nesse quadro, a democracia brasileira conviveu nos últimos trinta anos com “instituições semi-republicanas". Apesar da tentativa constante de realizar a republicanização delas (GUIMARÃES, 2017, p. 136), não houve, contudo, alteração nos "fundamentos democráticos do poder" (GUIMARÃES, 2019b, p. 08). Ou melhor, dos "fundamentos antirepublicanos de reprodução da democracia brasileira" (GUIMARÃES, 2017, p. 136).

Assim, apesar das conquistas de direitos sem precedentes - ligados ao trabalho, à saúde, à assistência e à educação (GUIMARÃES, 2017, p. 136) —, acompanhados da formação de um sistema eleitoral mais inclusivo - capaz de abarcar e incluir a maioria da população (GUIMARÃES, 2019b, p. 08) —, os avanços no campo democrático foram limitados (GUIMARÃES, 2017, p. 136).

Ao lado dos supracitados êxitos, não houve a democratização sobre o "controle" das Forças Armadas e sobre "o aparato de segurança pública”, houve uma maior concentração do "poder midiático" (GUIMARÃES, 2019b, p. 08), as dimensões "não democráticas do Judiciário" permanecem presentes, bem como a manutenção, em grande medida, de um sistema eleitoral formulado no período ditatorial - ligado a "procedimentos antirrepublicanos que vieram a se estabilizar naquilo que foi sendo chamado [...] de presidencialismo de coalizão" (GUIMARÃES, 2019b, p. 09). Por fim, a experiência constitucional iniciada em 1988 também não conseguiu sedimentar "a questão dos direitos das mulheres no sistema político brasileiro" e continua presente, ainda que em menor medida, "um racismo institucional" (GUIMARÃES, 
2019b, p. 09). Essa é a contradição presente na Constituição: há "uma proclamação muito viva, muito forte, histórica, dos direitos humanos, e uma ainda precária democratização dos fundamentos e da reprodução do poder político" (GUIMARÃES, 2019b, p. 09). Seus avanços, portanto, não foram capazes de fazer com que os fundamentos antirrepublicanos da democracia fossem alterados (GUIMARÃES, 2018a, p. 136).

Além disso, para Juarez Guimarães, recentemente, nossa experiência constitucional foi desestabilizada. Com o impeachment da presidenta Dilma Rousseff sem crime de responsabilidade houve um "impedimento da democracia" (GUIMARÃES, 2019a, p. 251). O “golpe parlamentar de 2016" (GUIMARÃES, 2019a, p. 250) interrompeu a experiência democrática iniciada em 1988 (GUIMARÃES, 2019b, p. 08). ${ }^{5}$ A partir desse momento, então, estaria encerrado, entre conquistas e contradições, o período de 28 anos de vitória dos direitos humanos sobre o medo e a violência (GUIMARÃES, 2019a, p. 250).

E é esse o período atual da história do constitucionalismo e da democracia brasileira. Um "momento crítico, de encruzilhada" (GUIMARÃES, 2019, p. 249), pois, apesar da realização do golpe,

[...] os ataques aos direitos fundamentais contidos na Constituição de 1988 não foram externos à institucionalidade democrática vigente, nem concentrados em um só momento, nem mesmo abertamente disruptivos em relação à vigência da própria Constituição. A Constituição de 1988 não foi abolida. Não houve atos institucionais. Não se praticou um golpe militar, em um sentido histórico tradicional (GUIMARÃES, 2019a, p. 251).

Com o fim do período de estabilidade democrática - mesmo com as dificuldades desse diagnóstico (GUIMARÃES, 2019a, p. 251) —, configurou-se uma "situação de regime de exceção" constitucional (GUIMARÃES, 2019a, p. 252) expressa em uma aparente contradição: a Constituição "continua vigente” (GUIMARÃES, 2019a, p. 252), apesar de não estar em "plena vigência” (GUIMARÃES, 2019a, p. 251).

Essa aparente contradição se expressa nos ataques incessantes e violentos aos direitos conquistados e aos fundamentos constitucionais. No limite, houve uma alteração radical nos alicerces do poder, que deixou de estar ancorado "na soberania popular" e "se estabeleceu em rompimento com ela" (GUIMARÃES, 2019b, p. 09). Assim, as "dimensões fundamentais do pacto constitucional de 1988 foram rompidos" (GUIMARÃES, 2019a, p. 251). ${ }^{6}$

\footnotetext{
5 Segundo o professor esse processo culminou com a eleição de Jair Bolsonaro e do "General Mourão" como "presidente e vice-presidente" da República, em uma campanha eleitoral flagrantemente avessa "à própria ideia de direitos humanos" (GUIMARÃES, 2019a, p. 250).

${ }^{6}$ Entre as violações à ordem constitucional podem ser apresentados: "Violações do princípio de maioria e do pluralismo no regime presidencialista" (GUIMARÃES, 2019a, p. 252); "Passagem de uma dinâmica de aberta judicialização à defesa explícita do poder ilimitado do STF em interpretar e arbitrar sem limites a Constituição"
} 
A ruptura constitucional e a crise democrática brasileiras, todavia, não devem ser compreendidas de modo redutor, considerando o Brasil como um caso isolado e buscando as suas causas somente na história nacional. Pelo contrário, para uma compreensão adequada sobre o tempo presente é necessário levar a sério toda a sua complexidade. É preciso enquadrar o caso brasileiro em um contexto global, pois esse cenário não é o resultado de uma incapacidade dos brasileiros e das brasileiras, nem a consequência de uma suposta especificidade nacional que impede a realização e a vivência de uma sociedade democrática. Trata-se de um caso de "corrosão" das garantias e dos direitos presentes nas "Constituições do pós-guerra" em diferentes Estados (GUIMARÃES, 2019a, p. 257). Um fenômeno global que se expressa e se cristaliza de distintas formas em diferentes localidades.

Assim, o caso brasileiro seria "não propriamente uma exceção mas uma singularidade vivida de forma extremamente dramática em uma tendência de época" (GUIMARÃES, 2019a, p. 257). Isto é, ao mesmo tempo em que deve ser considerado dentro de um quadro global de corrosão, referidas especificidades precisam ser sempre consideradas para uma compreensão adequada da realidade brasileira.

Da mesma forma, não deve haver uma romantização em relação à Constituição de 1988. A democracia e a ordem constitucional brasileiras mesmo em momentos de normalidade não devem ser entendidas como conquistas absolutas e como sendo formas plenamente consolidadas (GUIMARÃES, 2019a, p. 256). É necessário levar sempre em consideração que a "imprevisão" faz parte da democracia e que o conflito é sua parte constitutiva (GUIMARÃES; MOREIRA, 2018, p. 05). Democracia e constituição convivem constantemente com a possibilidade de serem subvertidas. Retrocessos, portanto, sempre são possíveis. Em verdade, esse é o "fundamento do pacto político, nunca inteiramente estabilizado mas sempre em disputa” (GUIMARÃES, 2019a, p. 256).

Toda Constituição se funda em um pacto de forças políticas que organiza o conflito de interesses e de poder em um arranjo legal de instituições, o qual, por sua vez, se assenta em um certo campo de valores compartilhados. A desestabilização constitucional hoje em processo no Brasil é provocada por uma corrosão desses valores compartilhados e pela incapacidade das instituições em processar, em seus

(GUIMARÃES, 2019a, p. 253); "Desconstitucionalização da obrigação do Estado brasileiro em prover a defesa dos direitos do trabalho e os direitos sociais previstos na Constituição de 1988" (GUIMARÃES, 2019a, p. 254); “Tutela militar passou a ganhar foros de legitimidade, seja no exercício do STF, seja através da ocupação massiva de cargos no Executivo, seja através da comemoração pública do golpe de 1964 com patrocínio inconstitucional do próprio presidente da República" (GUIMARÃES, 2019a, p. 254); “Os princípios mínimos da soberania nacional, previstos na Constituição de 1988, passaram a ser abertamente violados e minados"; "Legitimação e aberta legalização dos discursos de ódio na cultura brasileira (GUIMARÃES, 2019a, p. 255); “Adoção de um tal regime de privatização da vida pública que, na prática, esvazia qualquer sentido de combate à corrupção sistêmica" (GUIMARÃES, 2019a, p. 255). 
procedimentos constitucionalizados, os conflitos fundamentais entre as classes (GUIMARÃES, 2019a, p. 256).

Contudo, o que ocorreu em 2016 não foi apenas mais um momento de disputa, mas o rompimento do próprio pacto, bem como de seus fundamentos. Portanto, para Juarez Guimarães, devido ao desligamento da ordem constitucional dos valores compartilhados, à perda de fundamento na soberania popular, aos ataques e violações centrais à Constituição "não há mais como voltar a 1988" (GUIMARÃES, 2019a, p. 256). Assim, propõe a necessidade da reconstituição de um pacto democrático, "que restabeleça os valores, as instituições e os procedimentos da disputa democrática pluralista". Como desdobramento, torna-se necessário também a reconstrução da ordem constitucional, isto é, a constituição de uma nova constituição (GUIMARÃES, 2019a, p. 257).

Uma nova constituição se justificaria por dois motivos: o primeiro, devido ao intenso e inegável processo "desconstitucionalização" presente na realidade brasileira. Em segundo lugar, essa propositura está ancorada na necessidade de oferecer uma saída democrática para a crise de "regime político" (GUIMARÃES, 2019a, p. 259).

Nesse quadro, a tarefa de reconstrução é complexa, pois abarca os próprios "fundamentos da democracia, da soberania popular e da soberania nacional, e construir uma nova fase dos direitos humanos" (GUIMARÃES, 2019a, p. 259). E se assenta, no limite, na defesa dos próprios fundamentos de uma ordem constitucional democrática.

Portanto, não se trata de uma defesa ingênua e "incondicionada" por uma nova constituição. Ela não é o início, mas é o resultado "de um processo político de luta democrática" contra os constantes ataques e violações (GUIMARÃES, 2019a, p. 258). Assim, o seu ponto de partida é a coligação das forças progressistas brasileiras (GUIMARÃES, 2019a, p. 257) em nome de um projeto "pluralista" e em defesa da "soberania popular". A nova constituição é a resposta que emerge das próprias lutas sociais "por seus direitos fundamentais" (GUIMARÃES, 2019a, p. 258), é a expressão da busca por recuperar os fundamentos rompidos com o golpe de 2016.

Devido ao exposto, mesmo ao afirmar que houve um "impedimento da democracia" (GUIMARÃES, 2019a, p. 251), seguido por um regime de exceção (GUIMARÃES, 2019a, p. 252), ou na sua proposta por uma nova constituição, em nenhum desses momentos, Juarez Guimarães parece ter deixado de afirmar a necessidade de uma defesa da Constituição e da ordem constitucional. Pelo contrário, toda a sua argumentação parece ser desenvolvida buscando sua proteção, pois, segundo ele, na atual conjuntura, é "legítimo uma postura garantista, isto é, que se orienta no horizonte político da defesa dos direitos previstos na 
Constituição de 1988” (GUIMARÃES, 2019a, p. 252). Nesse cenário, não é cabível uma omissão em relação à Constituição, é necessário lutar com e por ela, pois agir de qualquer outra forma levaria a perder "de antemão uma disputa ainda em processo" (GUIMARÃES, 2019a, p. 252).

Essa mesma postura permanece presente na sua defesa por uma nova constituição. Uma vez que ela se ancora no rompimento do pacto político estabelecido e no afastamento da soberania popular. Em outros termos, no afastamento da Constituição dos fundamentos democráticos e populares da própria Constituição, expressando a impossibilidade de "voltar a 1988” (GUIMARÃES, 2019a, p. 256).

Sendo assim, mesmo reconhecendo os limites e contradições da Constituição, a proposta é uma nova constituição que resgate os seus alicerces. Juarez Guimarães, mais uma vez, não renuncia à Constituição, ele afirma que é "imperioso defender as conquistas democráticas de 1988 e as que foram a ela acrescentadas no período democrático que vai de 1988 a 2016" (GUIMARÃES, 2019a, p. 256). E, é a partir dessa não renúncia à Constituição que é possível estabelecer uma ponte entre seu trabalho e o de Carvalho Netto.

\section{MENELICK DE CARVALHO NETTO E JUAREZ GUIMARÃES NOS 30 ANOS DA CONSTITUIÇÃO}

É na defesa incondicionada de uma constituição e de uma ordem constitucional nunca plenamente consolidada e, por isso mesmo, sempre em disputa, que os projetos teóricos desenvolvidos por e em torno de Juarez Guimarães e Menelick de Carvalho Netto se aproximam. Talvez, em Juarez Guimarães, haja uma compreensão mais restrita sobre o que é uma constituição em face da de Menelick de Carvalho Netto, que o leva a entender que a partir de 2016 se vive um Estado de exceção no Brasil. Apesar disso, ambos os autores afirmam em alto e bom som os avanços conquistados desde 1988 e a urgência de lutar pela Constituição com a Constituição.

Ao compreender que houve um excessivo distanciamento da Constituição da soberania popular, dando espaço para uma lógica outra, não apenas diferente, mas que rompe com ela própria, a Constituição (GUIMARÃES, 2019b, p. 09), Juarez Guimarães chega à conclusão de que 2016 impede um retorno a 1988 (GUIMARÃES, 2019a, p. 256). Tudo isso devido aos ataques aos elementos centrais desta mesma Constituição que comprometeriam sua plena vigência. 
Por outro lado, a mesma conclusão não se mostra imperativa a partir da compreensão de Menelick de Carvalho Netto sobre a Constituição. Ao incorporar os avanços e retrocessos, assim como a manutenção de uma tensão constante como constituinte da própria Constituição, Carvalho Netto possibilita uma compreensão da Constituição a partir da qual os eventos ocorridos em 2016 não comprometeriam sua vigência ou inviabilizariam seu projeto. O que, por sua vez, também não se equivale a desconsiderar a gravidade de 2016.

Para Carvalho Netto, 2016 consistiu em um momento de manifestação das tensões constituintes da Constituição. Isto é, das disputas em torno do próprio significado da Constituição, “pois não há garantia de não-retrocesso [...]. É claro que a Constituição não pode impedir um golpe de Estado: ele existe, é possível e pode vir” (CARVALHO NETTO, 2019, p. 286).

No entanto, é imperativo que se enfrente esses momentos a partir de um maior tensionamento do significado do projeto da Constituição de 1988. Isso, porque, como em Carvalho Netto (2006, p. 23), “já há muito sabemos que textos constitucionais por si sós nada ou muito pouco significam. O problema é o de qual aplicação somos capazes de dar a eles" .

Nesse sentido, é possível afirmar que a compreensão de constituição apresentada por Guimarães é mais restrita do que a de Carvalho Netto, pois aquele compreende de um modo um pouco mais limitado as disputas por e em torno da Constituição que se catalisaram em 2016. Enquanto para Guimarães não é mais possível disputar o projeto constitucional de 1988, pois teria havido um afastamento da soberania popular a partir de 2016, em Carvalho Netto, por sua vez, esse é mais um momento na história constitucional brasileira, marcado por um forte retrocesso, mas que permanece vivo e ainda possível de ser disputado.

Não obstante as divergências nas conclusões, é no interior da própria obra de Juarez Guimarães que se encontram os elementos que tornam possível uma reconciliação entre as propostas dos autores em direção a uma defesa robusta da Constituição na efeméride dos seus 30 anos. Em ambas as abordagens, a Constituição traz em si um caráter provisório e imprevisto, de construção contínua e não plenamente consolidada. Em outros termos, talvez falte a Juarez Guimarães levar a sério a sua própria compreensão de que constituição e democracia são processos "nunca inteiramente estabilizado mas sempre em disputa" (GUIMARÃES, 2019a, p. 256).

A partir disso, seria possível aproximar Guimarães da compreensão de Carvalho Netto sobre a Constituição. Isto é, de que a "Constituição não é só um texto, é aquilo que ela produz: uma comunidade de princípios" (CARVALHO NETTO, 2019, p. 385), "uma comunidade em interlocução de nós conosco mesmos: quem somos nós e para onde vamos" (CARVALHO 
NETTO, 2019, p. 384) e pelas disputas constantes que ocorrem em seu interior, "por igualdade e liberdade em uma tensão constitutiva de uma sociedade complexa" (CARVALHO NETTO, 2019, p. 385).

Cabe ressaltar que os supracitados autores também compreendem de modo distinto o processo de transição pós-ditadura civil-empresarial-militar. Ao focar nas instituições construídas a partir de 1988, Juarez Guimarães conclui por uma transição por transação, assim como compreende uma parcela significativa dos constitucionalistas e dos cientistas políticos brasileiros. ${ }^{7}$ Isto é, uma transição coordenada por elites que, em última análise, objetivavam permanecer no poder e por isso controlaram em grande medida os contornos adquiridos pelas instituições democráticas, tanto é que essas instituições não se diferenciariam significativamente daquelas existentes no regime militar.

Em contrapartida, ao analisar o processo de constitucionalização brasileiro, Carvalho Netto destaca a influência da sociedade civil no resultado final dos trabalhos constituintes ocorridos em 1987-1988, classificando-o como o processo constituinte mais democrático da história constitucional brasileira (CARVALHO NETTO, 2019, p. 384). Na sua leitura, a participação popular nos processos deliberativos estatal não se encerrou neste momento. Ainda hoje, a atuação dos movimentos sociais no pós-1988 dá mostras inequívocas de que o significado desta mesma Constituição continua em disputa. Dessa forma, ganham destaque as conquistas possibilitadas pela Constituição de 1988, como o fortalecimento de uma noção de direitos humanos e uma crescente inclusão de setores da população que historicamente estiveram alijados do processo democrático.

Talvez essas perspectivas possam ser justapostas, indicando como os avanços no processo de democratização são constantemente limitados pelas heranças institucionais; indicando como as heranças institucionais são questionadas por alterações advindas do processo

7 Tradicionalmente, a transição brasileira foi considerada como uma transição por transação, por constitucionalistas que trataram o período como um pacto entre elites. O que torna mais compreensível a forma como Juarez Guimarães aborda a questão. Essa compreensão de Guimarães também está presente em outros autores das ciências sociais, como, Cf.: NOBRE, Marcos. Imobilismo em movimento - Da abertura democrática ao governo Dilma. 1. ed. São Paulo: Companhia das Letras, 2013. p. 27-65. Ademais, esse entendimento também foi apresentado pelos Ministros Eros Grau e Gilmar Mendes, quando do julgamento da ADPF 153, pelo STF, em que foi discutida a compatibilidade da Lei de Anistia com a Constituição de 1988. Nessa oportunidade, o ministro Eros Grau faz referência a uma transição “[...] suave em razão de certos compromissos” (BRASIL, 2010, p. 37). E também a Advocacia Geral da União já havia manifestado o mesmo entendimento, ao afirmar que o "diploma legal surgiu da negociação havida entre a sociedade civil e o regime militar, que possibilitou, à época, a transição para o regime democrático. Dessa forma, assegurou-se, com a lei, que ambos os lados seriam beneficiados com a anistia, evitando-se, inclusive, qualquer espécie de revanchismo no novo governo" (BRASIL, 2009, p. 12). Nesse sentido: FERREIRA FILHO, Manoel Gonçalves. O poder constituinte. 2. Ed. São Paulo: Saraiva, 1985. Para uma crítica a essa concepção de transição por transação ver: MEYER, Emilio Peluso Neder. Ditadura e Responsabilização: Elementos para uma Justiça de Transição no Brasil. Belo Horizonte: Arraes, 2012. 
de democratização; indicando como as heranças institucionais influem nas condições de possibilidade do processo de democratização; indicando como o processo de democratização é condição de possibilidade para alterações institucionais. Em resumo, ambas as perspectivas estão em constante tensão, o que permite retomar o ponto compartilhado por Carvalho Netto e Guimarães, quanto à não estagnação e imprevisibilidade de uma constituição.

Juarez Guimarães e Menelick de Carvalho Netto compartilham, em última análise, a crença na constituição como única alternativa democrática possível e, exatamente por isso, imprescindível. Assim, se é possível destacar um aprendizado necessário com o projeto da Constituição de 1988 é a imperatividade de uma constituição como única alternativa democrática. Constituição essa que, compreendida como um processo dinâmico e em constante tensão consigo mesma, é sempre imprevisível. Uma Constituição que trás consigo o potencial transformador de um processo constituinte que não se encerra em si mesmo, como em Carvalho Netto, assim como o potencial de alterar as heranças institucionais que marcaram e marcam a história do constitucionalismo brasileiro, como em Guimarães.

Em ambas as perspectivas teóricas, a ativação do potencial transformador desta Constituição passa pela atuação de uma sociedade civil ativa. Isso fica evidente quando se tem em vista o tratamento conferido pelas propostas teóricas de Carvalho Netto e Guimarães ao impeachment da presidenta Dilma Rousseff.

Para Carvalho Netto (2019, p. 387), pode-se "afirmar, pela ausência de crime de responsabilidade, que se tratou de um golpe". Contudo, "esse mesmo golpe, ao contrário de apontar para uma não vigência da Constituição de 1988, em verdade reafirma a necessidade de nosso engajamento em defesa dessa mesma Constituição". Nas suas palavras, "é precisamente em tempos de negação da Constituição que mais devemos insistir em seu papel contrafático". E essa insistência no papel contrafático da Constituição, para Carvalho Netto, "deve vir da sociedade civil organizada, que deve superar sua apatia do presente, não abrindo mão da Constituição de 1988".

Como visto no decorrer deste trabalho, Guimarães (2019a, p. 251) também compreende o impeachment da presidenta Dilma Rousseff como um golpe, devido à ausência de crime de responsabilidade. E, assim como Carvalho Netto, Guimarães (2016, p. 1) também aposta na sociedade civil ativa, ou se for preferível, na força do "povo soberano", que da perspectiva do "republicanismo democrático", seria o verdadeiro "guardião da Constituição", como ator responsável em fazer frente às tentativas de subversão desta mesma Constituição.

Mesmo sustentando a necessidade de uma nova constituinte o que, à primeira vista, poderia sugerir um ponto de afastamento em relação à proposta teórica de Carvalho Netto, o 
fato é que a proposta de Guimarães não está descolada de uma defesa dos fundamentos do pacto político de 1988. Conforme aqui também já explicitado, é o próprio autor quem defende a necessidade de resgate desses fundamentos, em razão do golpe parlamentar ocorrido em 2016 (GUIMARÃES, 2019a, p. 256). Isso se torna evidente quando Guimarães (2019a, p. 258) reconhece que o processo constituinte por ele sustentado não é um ponto de partida, mas de chegada, levando à compreensão de que, da sua perspectiva, uma democracia constitucional não está, nem pode estar, desvinculada da atuação de uma sociedade civil ativa em defesa de iguais direitos de igualdade e liberdade.

\section{CONSIDERAÇÕES FINAIS}

A partir das concepções de Carvalho Netto e Guimarães, tem-se que as conquistas obtidas a partir do projeto de Constituição inaugurado em 1988 são essenciais para a compreensão do atual momento do constitucionalismo brasileiro (situado em um contexto mais amplo de desafios que se apresentam ao constitucionalismo no cenário internacional) e das possibilidades que agora se apresentam. Isso porque esses avanços e retrocessos permitem visualizar como o processo de democratização brasileiro sempre esteve sujeito a tensionamentos e disputas.

O atual momento constitucional é mais um desses momentos de especial tensionamento, em que é posta uma "encruzilhada" (GUIMARÃES, 2019a, p. 249), mas sem representar uma ruptura. O que, por sua vez, demanda a utilização da própria Constituição para defender a democracia e a ordem constitucional. Compreender que a Constituição está aberta às significações conferidas pela sociedade é reconhecer que ela mesma, a Constituição, não está encerrada e tampouco limitada ao seu texto (CARVALHO NETTO, 2019, p. 385), razão pela qual ainda se pode continuar acreditando na democracia e na Constituição, ou, em outras palavras, nos fundamentos do pacto político de 1988, pois "mesmo a esperança da democracia precisa ter suas razões" (GUIMARÃES; MOREIRA, 2018, p. 06).

\section{REFERÊNCIAS BIBLIOGRÁFICAS}

CARVALHO NETTO, Menelick de. A hermenêutica constitucional e os desafios postos aos direitos fundamentais. In. SAMPAIO, José Adércio Leite (org.). Jurisdição constitucional e direitos fundamentais. Belo Horizonte: Del Rey, 2003, p. 141-163.

CARVALHO NETTO, Menelick de. Prefácio - A urgente revisão da teoria do poder constituinte: da impossibilidade da 
democracia possível. In. CATTONI, Marcelo. Poder Constituinte e patriotismo constitucional: $\mathrm{o}$ projeto constituinte do Estado Democrático de Direito na Teoria Discursiva de Jürgen Habermas. Belo Horizonte: Mandamentos, 2006, p. 19-28.

CARVALHO NETTO, Menelick de. Temporalidade, constitucionalismo e democracia. Humanidades, Brasília, n. 58, jun. 2011, p. 32-42.

CARVALHO NETTO, Menelick de. A comunidade de princípios inaugurada em 1988 e o papel do Estado na esfera pública. In. Revista de Ciências do Estado, v. 3, n. 2, 2018, p. 348-364.

CARVALHO NETTO, Menelick de. A tensão entre memória e esquecimento nos 30 anos da Constituição de 1988. In. CATTONI DE OLIVEIRA, Marcelo Andrade; GOMES; David F. L. (Orgs.). 1988-2018: O QUE CONSTITUÍMOS? Homenagem a Menelick de Carvalho Netto nos 30 Anos da Constituição de 1988. Belo Horizonte: Conhecimento, 2019, p. 383-387.

CATTONI DE OLIVEIRA, Marcelo Andrade; GOMES; David F. L. (Orgs.). 1988-2018:O QUE CONSTITUÍMOS? Homenagem a Menelick de Carvalho Netto nos 30 Anos da Constituição de 1988. Belo Horizonte: Conhecimento, 2019.

FERREIRA FILHO, Manoel Gonçalves. O poder constituinte. 2. Ed. São Paulo: Saraiva, 1985.

GUIMARÃES, J. R.. O povo soberano é o guardião da Constituição.In. Carta Maior,
$2016 . \quad$ Disponível em: <https://www.cartamaior.com.br/?/Editoria /Politica/O-povo-soberano-e-o-guardiaoda-Constituicao/4/35741>. Acesso em: 13 mar. 2020.

GUIMARÃES, J. R.. A Revolução democrática e o momento lefortiano da democracia brasileira. In.Cadernos de Ética e Filosofia Política (USP), v. 32, p. 123-140, 2017.

GUIMARÃES, J. R.; MOREIRA, M. S.. A imprevisibilidade democrática. In.Revista Brasileira de Ciências Sociais, v. 1, p. 1-7, 2018.

GUIMARÃES, J. R.. A Democracia Impedida e a Refundação Democrática no Brasil. In. CATTONI DE OLIVEIRA, Marcelo Andrade; GOMES; David F. L. (Orgs.). 1988-2018: $\quad$ O QUE CONSTITUÍMOS?: Homenagem a Menelick de Carvalho Netto nos 30 Anos da Constituição de 1988. Belo Horizonte: Conhecimento, 2019a, p. 249-260.

GUIMARÃES, J.R.; GOMES, D. F. L.; CAMPOS, G. A.; CARVALHO, Y. C. U.. A liberdade é republicana e socialista. In. Revista de Ciências do Estado, v. 4, p. 111, 2019b.

MEYER, Emilio Peluso Neder. Ditadura e Responsabilização: Elementos para uma Justiça de Transição no Brasil. Belo Horizonte: Arraes, 2012.

NOBRE, Marcos. Imobilismo em movimento: Da abertura democrática ao governo Dilma. São Paulo: Companhia das Letras, 2013.

A CONVERSATION BETWEEN MENELICK DE CARVALHO NETTO AND JUAREZ GUIMARÃES IN THE FRAMEWORK OF 30 YEARS OF THE 1988 CONSTITUTION

Almir Megali Neto | Jessica Holl | Rayann Kettuly Massahud de Carvalho 
How to cite this article: NETO, Almir Megali; HOLL, Jessica; CARVALHO, Rayann Kettuly Massahud de. Uma conversa com Menelick de Carvalho Netto e Juarez Guimarâes no marco dos 30 anos da Constituição de 1988. Revista de Ciências do Estado. Belo Horizonte: v. 5, n. 2, e20030. ISSN: 2525-8036.

Abstract: This work aims to juxtapose the main ideas exposed by Professors Menelick de Carvalho Netto and Juarez Guimarães about the 30th anniversary of the 1988 Constitution, present in their articles contained in the book"O Que Constituímos? Homenagem a Menelick de Carvalho Netto nos 30 Anos da Constituição de 1988" (CATTONI DE OLIVEIRA; GOMES, 2019) and in the interviews they granted to the Revista de Ciências do Estado of the Federal University of Minas Gerais (in the years 2018 and 2019). From the study of these works, it can be concluded that, although their conceptions about the Brazilian Constitution initially indicated a divergence, in fact both demonstrate the same constitutional loyalty, starting, however, from distinct concepts about the very idea of constitutionalism. And, from this dialogue, it is also possible to conclude that it is necessary to understand the current moment of Brazilian constitutionalism on the basis of the achievements obtained with the Constitution inaugurated in 1988. Thus, it is imperative to use the Constitution itself, placed in a moment of special tension, as a tool for the defense of democracy and the constitutional order.

Keywords: 30 years of the Brazilian Constitution; Menelick de Carvalho Netto; Juarez Guimarães. 